\title{
Reduced skeletal muscle mitochondrial respiration and improved glucose metabolism in nondiabetic obese women during a very low calorie dietary intervention leading to rapid weight loss.
}

Citation for published version (APA):

Rabol, R., Svendsen, P. F., Skovbro, M., Boushel, R., Haugaard, S. B., Schjerling, P., Schrauwen, P., Hesselink, M. K., Nilas, L., Madsbad, S., \& Dela, F. (2009). Reduced skeletal muscle mitochondrial respiration and improved glucose metabolism in nondiabetic obese women during a very low calorie dietary intervention leading to rapid weight loss. Metabolism-Clinical and Experimental, 58(8), 1145-1152. https://doi.org/10.1016/j.metabol.2009.03.014

Document status and date:

Published: 01/01/2009

DOI:

10.1016/j.metabol.2009.03.014

Document Version:

Publisher's PDF, also known as Version of record

Document license:

Taverne

Please check the document version of this publication:

- A submitted manuscript is the version of the article upon submission and before peer-review. There can be important differences between the submitted version and the official published version of record. People interested in the research are advised to contact the author for the final version of the publication, or visit the DOI to the publisher's website.

- The final author version and the galley proof are versions of the publication after peer review.

- The final published version features the final layout of the paper including the volume, issue and page numbers.

Link to publication

\footnotetext{
General rights rights.

- You may freely distribute the URL identifying the publication in the public portal. please follow below link for the End User Agreement:

www.umlib.nl/taverne-license

Take down policy

If you believe that this document breaches copyright please contact us at:

repository@maastrichtuniversity.nl

providing details and we will investigate your claim.
}

Copyright and moral rights for the publications made accessible in the public portal are retained by the authors and/or other copyright owners and it is a condition of accessing publications that users recognise and abide by the legal requirements associated with these

- Users may download and print one copy of any publication from the public portal for the purpose of private study or research.

- You may not further distribute the material or use it for any profit-making activity or commercial gain

If the publication is distributed under the terms of Article 25fa of the Dutch Copyright Act, indicated by the "Taverne" license above,

Download date: 26 Apr. 2023 


\title{
Reduced skeletal muscle mitochondrial respiration and improved glucose metabolism in nondiabetic obese women during a very low calorie dietary intervention leading to rapid weight loss
}

\author{
Rasmus Rabøl ${ }^{\mathrm{a}, \mathrm{b}, *}$, Pernille F. Svendsen ${ }^{\mathrm{c}}$, Mette Skovbro $^{\mathrm{a}}$, Robert Boushel ${ }^{\mathrm{a}}$, Steen B. Haugaard ${ }^{\mathrm{d}}$, \\ Peter Schjerling $^{\mathrm{a}, \mathrm{e}}$, Patrick Schrauwen ${ }^{\mathrm{f}, \mathrm{g}}$, Matthijs K.C. Hesselink ${ }^{\mathrm{f}, \mathrm{g}}$, Lisbeth Nilas ${ }^{\mathrm{c}}$, \\ Sten Madsbad ${ }^{\mathrm{b}}$, Flemming Dela ${ }^{\mathrm{a}}$ \\ ${ }^{a}$ Center for Healthy Aging, Department of Biomedical Sciences, Faculty of Health Sciences, University of Copenhagen, DK-2200 Copenhagen, Denmark \\ ${ }^{\mathrm{b}}$ Department of Endocrinology, Hvidovre University Hospital, University of Copenhagen, DK-2650 Hvidovre, Denmark \\ ${ }^{\mathrm{c}}$ Department of Gynecology and Obstetrics, Hvidovre University Hospital, University of Copenhagen, DK-2650 Hvidovre, Denmark \\ ${ }^{\mathrm{d}}$ Clinical Research Centre, Hvidovre University Hospital, University of Copenhagen, DK-2650 Hvidovre, Denmark \\ e Institute of Sports Medicine, Bispebjerg Hospital, DK-2200 Copenhagen, Denmark \\ ${ }^{\mathrm{f}}$ Department of Human Biology, Maastricht University, NL-6200 MD Maastricht, The Netherlands \\ ${ }^{\mathrm{g}}$ Department of Movement Sciences, Maastricht University, NL-6200 MD Maastricht, The Netherlands
}

Received 19 May 2008; accepted 24 March 2009

\begin{abstract}
Reduced oxidative capacity of skeletal muscle has been proposed to lead to accumulation of intramyocellular triglyceride (IMTG) and insulin resistance. We have measured mitochondrial respiration before and after a $10 \%$ low-calorie-induced weight loss in young obese women to examine the relationship between mitochondrial function, IMTG, and insulin resistance. Nine obese women (age, 32.3 years [SD, 3.0]; body mass index, $33.4 \mathrm{~kg} / \mathrm{m}^{2}$ [SD, 2.6]) completed a 53-day (SE, 3.8) very low calorie diet (VLCD) of 500 to $600 \mathrm{kcal} / \mathrm{d}$ without altering physical activity. The target of the intervention was a $10 \%$ weight loss; and measurements of mitochondrial respiration, IMTG, respiratory exchange ratio, citrate synthase activity, mitochondrial DNA copy number, plasma insulin, 2-hour oral glucose tolerance test, and free fatty acids were performed before and after weight loss. Mitochondrial respiration was measured in permeabilized muscle fibers using high-resolution respirometry. Average weight loss was $11.5 \%(P<.05)$, but the levels of IMTG remained unchanged. Fasting plasma glucose, plasma insulin homeostasis model assessment of insulin resistance, and insulin sensitivity index (composite) obtained during 2-hour oral glucose tolerance test improved significantly. Mitochondrial respiration per milligram tissue decreased by approximately $25 \%(P<.05)$, but citrate synthase activity and mitochondrial DNA copy number remained unchanged. Respiratory exchange ratio decreased from 0.87 (SE, $0.01)$ to 0.79 (SE, 0.02) $(P<.05)$ as a sign of increased whole-body fat oxidation. Markers of insulin sensitivity improved after the very low calorie diet; but mitochondrial function decreased, and IMTG remained unchanged. Our results do not support a direct relationship between mitochondrial function and insulin resistance in young obese women and do not support a direct relationship between IMTG and insulin sensitivity in young obese women during weight loss.
\end{abstract}

(C) 2009 Elsevier Inc. All rights reserved.

\section{Introduction}

Obesity is a major threat to public health in the Western world. Obesity is tightly associated with insulin resistance that precedes and predicts the development of type 2 diabetes

* Corresponding author. Department of Internal Medicine, Section of Endocrinology, Yale University School of Medicine, The Anlyan Center, PO Box 208020, New Haven, CT 06520-0820, USA. Tel.: +1 203785 5447, +12035006027 (mobile).

E-mail address: rasmus.rabol@yale.edu (R. Rabøl). mellitus [1]. Accumulation of intramyocellular triglyceride (IMTG) is correlated to insulin resistance [2,3]. Elevated levels of IMTG have been found in young, lean, insulinresistant offspring of patients with type 2 diabetes mellitus, suggesting a role for defects in lipid metabolism as a cause of insulin resistance [4].

Mitochondrial function has been under intense investigation in recent years. It is still debated whether the reduction in muscular adenosine triphosphate (ATP) production seen in insulin resistance $[5,6]$ is due to intrinsic defects of the 
mitochondria [7] or due to reductions in mitochondrial number and density [8-10]. Furthermore, it has been difficult to establish whether decreased mitochondrial function is a prerequisite for accumulation of IMTG or whether IMTG inhibits mitochondrial function $[11,12]$.

The aim of this study was to examine the specific effects of weight loss induced by diet alone on IMTG, glucose metabolism, and skeletal muscle mitochondrial function in obese women. We treated 9 obese women with a very low calorie diet (VLCD) to test the hypothesis that VLCD would decrease IMTG and improve glucose metabolism in parallel with improvements in mitochondrial function. We sought to examine the independent effect of caloric restriction dietinduced weight loss on IMTG, mitochondrial function, and insulin sensitivity apart from the effects of physical activity. This approach was taken because it is well known that increased physical activity will influence mitochondrial expression and could obscure conclusions about the relationship between weight loss by diet alone and mitochondrial function and other parameters of interest. The reason for using such a low-calorie diet was to induce significant weight loss in a short period in which we could ensure as high a compliance rate as possible.

Mitochondrial function was measured in permeabilized muscle fibers [8,13-15]. This method allows us to perform detailed measurements of the electron transport chain and study mitochondrial oxygen consumption ex vivo using high-resolution respirometry.

\section{Research design and methods}

\subsection{Subjects}

Seventeen young women were included in the study after advertising in the local paper. All women went through a general health examination before entering the study. Women with diabetes and other known chronic diseases were excluded from the study. Women who had used oral contraceptives or other drugs known to alter glucose and insulin metabolism, within the last 3 months, were also excluded from the study. All study subjects had a regular menstrual cycle. The study was conducted according to the principles expressed in the Declaration of Helsinki and approved by the ethics committee of Copenhagen and Frederiksberg municipality, Denmark. All study subjects gave written informed consent before entering the study.

All subjects were given individual instructions on how to follow the VLCD. They were allowed 500 to $600 \mathrm{kcal} / \mathrm{d}$, which was provided by NUPO (Greve, Denmark). The NUPO formula provides $307 \mathrm{kcal}$ per $100 \mathrm{~g}$ of powder (protein, $43 \mathrm{~g}$; carbohydrate, $20 \mathrm{~g}$; and fat, $5.8 \mathrm{~g}$ ). The participants were instructed to maintain normal daily activity and not change patterns of physical exercise. Habitual bicycling (used as a mode of transport), stair-walking, etc, were allowed during the period of treatment. The goal of the treatment was a $10 \%$ weight loss during the intervention period. Compliance with the diet and physical activity level was checked at weekly control visits, and instructions not to alter physical activity were reinforced. Individual weight loss curves are shown in Fig. 1.

On the study days, the subjects reported to the hospital at 8:00 AM after an overnight fast. Thirty-minute indirect calorimetry was performed using a computerized canopy gas analyzer system (Deltatrac II Metabolic Monitor; Datex, Helsinki, Finland). Fasting blood samples were obtained and immediately centrifuged at $4^{\circ} \mathrm{C}$; and plasma was stored at $-80^{\circ} \mathrm{C}$ for later analysis of plasma insulin (using the 1235 AutoDELPHIA automatic immunoassay system; Wallac Oy, Turku, Finland), plasma free fatty acids (FFAs) (using an enzymatic colorimetric method, Wako C test kit; Wako Chemicals, Neuss, Germany; with an interassay coefficient of variation of 5\%), and serum triiodothyronine (T3). Thyroid hormone levels were measured with a chemiluminescent assay (Architect CMIA; Abbott Laboratories, Abbott Park, IL, USA). A 2-hour oral glucose tolerance test (OGTT) (75 g glucose) was then performed. Plasma glucose was measured by the oxidase method (Beckman Glucose Analyzer, Fullerton, CA). Body composition was estimated by a whole-body dual-energy $\mathrm{x}$-ray absorptiometry scan that separately measured 3 of the principal compartments of the body (total bone mineral content, total lean body soft tissue mass, and total fat mass).

\subsection{Preparation of muscle fibers}

Skeletal muscle biopsies were obtained under local anesthetics using the Bergstrøm [16] technique with a needle

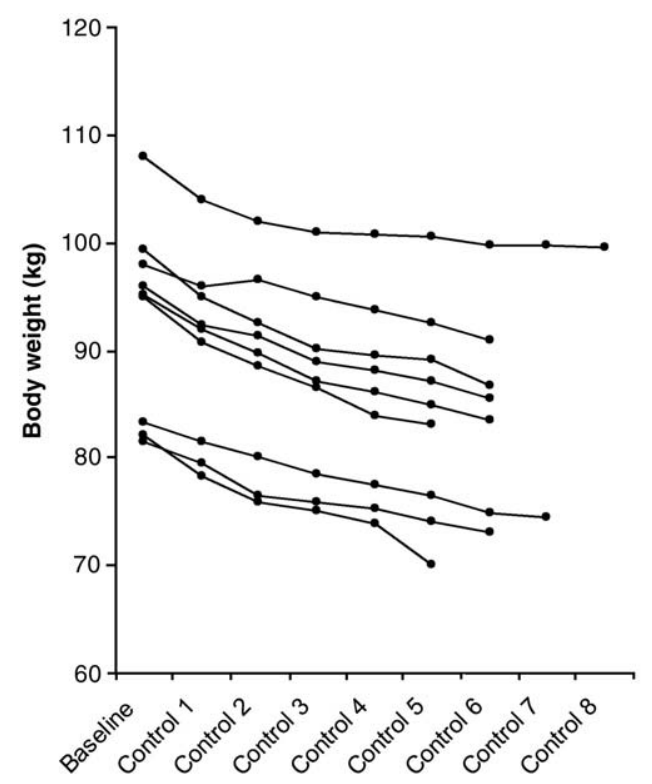

Fig. 1. Individual weight loss curves as a result of VLCD treatment. Compliance with the diet and physical activity level was checked at control visits, and instructions not to alter physical activity were reinforced. The subjects lost on average $11.5 \%$ of their baseline weight during the VLCD, with a mean length of VLCD treatment of 53 days (SE, 3.8). 
modified for suction. A large part of the biopsy was immediately frozen in liquid nitrogen at $-80^{\circ} \mathrm{C}$ for later analysis, whereas a small part $(5 \mathrm{mg})$ was immediately placed in ice-cold BIOPS solution containing $10 \mathrm{mmol} / \mathrm{L}$ Ca-EGTA buffer, $0.1 \mu \mathrm{mol} / \mathrm{L}$ free calcium, $20 \mathrm{mmol} / \mathrm{L}$ imidazole, $20 \mathrm{mmol} / \mathrm{L}$ taurine, $50 \mathrm{mmol} / \mathrm{L} \mathrm{K}-\mathrm{MES}(2-(\mathrm{n}-$ morpholino)-ethanosulfonic acid), $0.5 \mathrm{mmol} / \mathrm{L}$ dithiothreitol, $6.56 \mathrm{mmol} / \mathrm{L} \mathrm{MgCl}_{2}, 5.77 \mathrm{mmol} / \mathrm{L} \mathrm{ATP}$, and $15 \mathrm{mmol} / \mathrm{L}$ phosphocreatine ( $\mathrm{pH}$ 7.1).

Muscle samples were gently dissected using forceps, and fibers were incubated with $3 \mathrm{~mL}$ of saponin $(50 \mu \mathrm{g} / \mathrm{mL})$ for 30 minutes [13]. Respiration measurements were performed in medium Mir05 containing $0.5 \mathrm{mmol} / \mathrm{L}$ EGTA, $3 \mathrm{mmol} / \mathrm{L} \mathrm{MgCl}_{2}, 60 \mathrm{mmol} / \mathrm{L}$ K-lactobionate, $20 \mathrm{mmol} / \mathrm{L}$ taurine, $10 \mathrm{mmol} / \mathrm{L} \quad \mathrm{KH}_{2} \mathrm{PO}_{4}, 20 \mathrm{mmol} / \mathrm{L}$ HEPES, $110 \mathrm{mmol} / \mathrm{L}$ sucrose, and $1 \mathrm{~g} / \mathrm{L}$ bovine serum albumin ( $\mathrm{pH}$ 7.1). Measurements of oxygen consumption were performed at $37^{\circ} \mathrm{C}$ using the high-resolution Oroboros Oxygraph-2k (Oroboros, Innsbruck, Austria), and all additions of substrates and inhibitors are added in series. State 2 respiration was achieved by adding malate $(2 \mathrm{mmol} / \mathrm{L})$ and glutamate $(10 \mathrm{mmol} / \mathrm{L})$, whereas state 3 respiration was recorded after the addition of adenosine diphosphate (ADP) $(5 \mathrm{mmol} / \mathrm{L})$ to the chambers. State 3 with convergent electron input to both complex I and complex II was achieved by adding succinate $(10 \mathrm{mmol} / \mathrm{L})$. Maximal uncoupled respiration was recorded after the addition of carbonyl cyanide p-(trifluoromethoxy)phenylhydrazone (FCCP) in saturating amounts $(0.5-2 \mu \mathrm{mol} / \mathrm{L})$.

Using the technique of permeabilization allows us to study the mitochondria "in situ" in the cell, and very small biopsy samples $(5 \mathrm{mg})$ are needed to study the mitochondrial function using Oxygraph measurements [15].

\subsection{IMTG and glycogen measurements}

Before biochemical analysis, muscle samples were freeze dried and dissected free of connective tissue, visible fat, and blood using a stereomicroscope. Muscle glycogen concentration was determined as glucose residues after hydrolysis of the muscle sample in $1 \mathrm{~mol} / \mathrm{L} \mathrm{HCL}$ at $100^{\circ} \mathrm{C}$ for 2 hours [17]. Muscle triglyceride content was analyzed as described by Kiens and Richter [18]; the coefficient of variation of the assay is less than $5 \%$. In the final part of the analysis, the glycerol concentration was analyzed in triplicate on a CMA analyzer (CMA 600 Microdialysis Analyzer; CMA/Microdialysis, Stockholm, Sweden).

\subsection{Citrate synthase activity}

Citrate synthase activity was measured spectrophotometrically at $37^{\circ} \mathrm{C}$ on frozen muscle homogenates by 50 times dilution in a solution containing $100 \mu \mathrm{mol} / \mathrm{L}$ acetylcoenzyme A, $0.5 \mathrm{mmol} / \mathrm{L}$ nicotinamide adenine dinucleotide (NAD) (free acid), $1 \mathrm{mmol} / \mathrm{L}$ sodium malate, $8 \mu \mathrm{g} / \mathrm{mL}$ malate dehydrogenase (1200 U/mg, Boehringer, Mannheim, Germany), $2.5 \mathrm{mmol} / \mathrm{L}$ EDTA, and $10 \mathrm{mmol} / \mathrm{L}$ Tris-HCl
( $\mathrm{pH}$ 8.0). Enzyme activities are expressed as micromoles substrate per minute per gram dry weight muscle tissue.

\subsection{Calculation of insulin sensitivity indices}

Homeostatic model assessment of insulin resistance (HOMA-IR) values were calculated using the HOMA Calculator, version 2.2, software (Diabetes Trials Unit, University of Oxford). The software was downloaded from www.dtu.ox.ac.uk/homa. The composite insulin sensitivity index (ISIcomposite) was estimated by obtaining paired values of insulin and glucose in the fasting state before the OGTT and during OGTT at 30, 60, 90, and 120 minutes, respectively, as described [19].

\subsection{Uncoupling protein 3 measurements}

For uncoupling protein 3 (UCP3) determination, muscle biopsies were cut into $20-\mu \mathrm{m}$-thick cryosections. Forty of these sections were sampled into a 1.5-mL Eppendorf tube and homogenized on ice with a sonicator 3 times for 5 seconds in $250 \mathrm{~mL}$ phosphate-buffered saline $(\mathrm{pH} 7.3)$ containing $1 \mathrm{mmol} / \mathrm{L}$ EDTA and $0.4 \mathrm{mmol} / \mathrm{L}$ phenylmethylsulfonyl fluoride. To $100 \mathrm{~mL}$ of the muscle homogenate, $50 \mathrm{~mL}$ Laemmli sodium dodecyl sulfate (SDS) sample buffer was added and thereafter boiled for 4 minutes. Next, 13\% polyacrylamide gels containing $0.1 \%$ SDS were loaded with $5 \mu \mathrm{L}$ of each sample including a Protein Plus Marker (BioRad Laboratories, Veenendaal, the Netherlands). After 45 minutes of electrophoresis at $200 \mathrm{~V}$, all gels were stained with the same solution of Coomassie Brilliant Blue. Afterward, the gels were scanned with the Odyssey Infrared Imager (Licor; Westburg, Leusden, the Netherlands) at $700 \mathrm{~nm}$. All lanes were quantified for protein quantity between 15 and $150 \mathrm{kd}$ (in arbitrary units). After quantifying, equal amounts of protein were loaded on $13 \%$ polyacrylamide gels containing $0.1 \%$ SDS for Western blotting. All gels were run $(45$ minutes at $200 \mathrm{~V})$ and blotted (60 minutes at $100 \mathrm{~V}$ ) at the same time using the same buffer. Subsequently, all the blots were simultaneously incubated overnight at room temperature with the primary antibody UCP3. For detection of the UCP3, a rabbit polyclonal UCP3 antiserum (code 1331; kindly provided by LJ Slieker, Eli Lilly, Indianapolis, IN) prepared against a 20 -amino acid peptide (human sequence amino acid 147-166) was used in a dilution of 1:20 000. After incubation with the appropriate secondary antibody labeled with Infrared IRDye800 (Rockland, Gilbertsville, PA); (60 minutes at room temperature), blots were scanned at $800 \mathrm{~nm}$ with the Odyssey Infrared Imager. Uncoupling protein 3 was detected at approximately $30 \mathrm{kd}$, and the UCP 3 protein band was quantified using the Odyssey Infrared Imager (in arbitrary units). For a detailed description of the selectivity and specificity checks, see previous reports $[20,21]$. Uncoupling protein 3 content was expressed as arbitrary units. The precision protein standard was also used as control for the Odyssey infrared detection.

For data analysis, average baseline UCP3 was set at 100\%; and the change from baseline in percentage was calculated. 


\subsection{Mitochondrial DNA}

For measurement of mitochondrial DNA (mtDNA) content, DNA was isolated from approximately 10-mg muscle biopsies by proteinase $\mathrm{K}$ digestion at $55^{\circ} \mathrm{C}$ for 3 days. The $100-\mu \mathrm{L}$ digestion mix contained $50 \mathrm{mU}$ proteinase $\mathrm{K}$ (polymerase chain reaction [PCR] grade, Roche, Mannheim, Germany), $20 \mathrm{mmol} /$ $\mathrm{L}$ Tris- $\mathrm{HCl}(\mathrm{pH} 8.4)$, and $50 \mathrm{mmol} / \mathrm{L} \mathrm{KCl}$. After incubation at $80^{\circ} \mathrm{C}$ for 45 minutes, the remains were spun down; and the supernatant was diluted 200 times in Tris-EDTA plus $1 \mathrm{ng} / \mu \mathrm{L}$ Salmon Sperm DNA (Sigma, St. Louis, MO). Five microliters of this dilution was amplified in a $25-\mu \mathrm{L}$ PCR containing $1 \times$ Quantitect SYBR Green Master Mix (Qiagen, Hamburg, Germany) and $100 \mathrm{nmol} / \mathrm{L}$ of each primer. The amplification was monitored real-time using the MX3000P Real-time PCR machine (Stratagene, La Jolla, CA, USA). The primers were designed to target genomic DNA (myogenin promoter: AGG TGC TGT CAG GAA GCA AGG A and TAG GGG GAG GAG GGA ACA AGG A) or mtDNA (COX1: CCC CTG CCA TAA CCC AAT ACC A and CCA GCA GCT AGG ACT GGG AGA GA). The $C_{\mathrm{t}}$ values were related to a standard curve made with the cloned PCR products. These PCR products were constructed by TA cloning of the real-time PCR products into pDrive (Qiagen PCR Cloning Kit, Qiagen) followed by PCR amplification of single clones with M13 primers (CCA GGG TTT TCC CAG TCA CGA and AGC GGA TAA CAA TTT CAC ACA GGA) and purification with a PCR purification kit (High Pure PCR purification kit, Roche). These PCR products were then sequence verified (insertion opposite direction of lacZ); and via quantification by spectrophotometry $(260 \mathrm{~nm})$, a dilution series (the standard curve) was made in TE plus $1 \mathrm{ng} / \mu \mathrm{L}$ Salmon Sperm DNA (Sigma) with known number of molecules $(5 \times$ $10^{6}$ down to 10 molecules per PCR). Mitochondrial DNA content per genome was then calculated as the ratio of the molecules measured with the mtDNA primers and the genomic DNA primers for each sample.

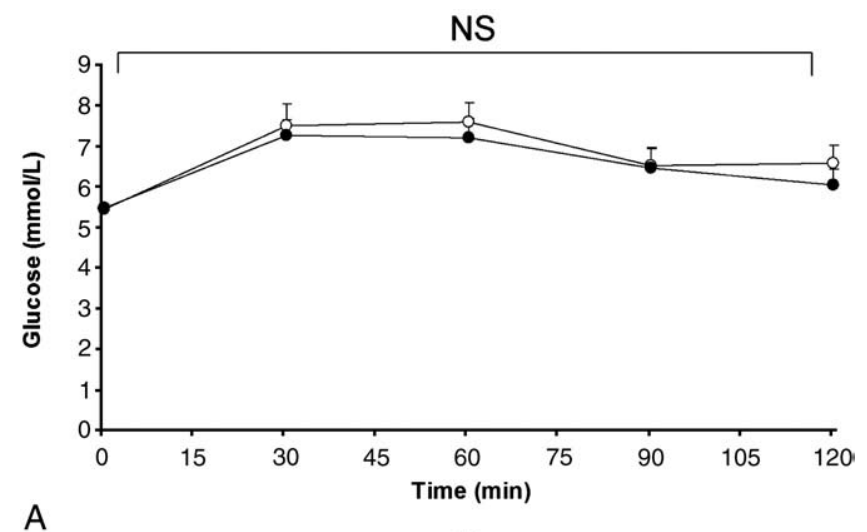

A

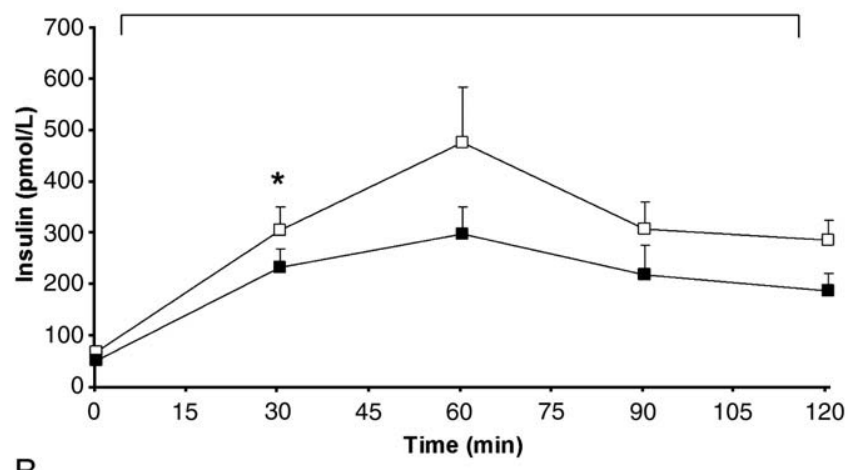

B

Fig. 2. Oral glucose tolerance test. A, Glucose values during a 2-hour OGTT before and after weight loss. Open circles $(O)$ show glucose values during OGTT before weight loss; closed circles $(\bullet)$ show glucose values after weight loss. B, Insulin values. Open squares $(\square)$ show insulin values during OGTT before weight loss; closed squares $(\square)$ show glucose values after weight loss. NS indicates not significant. ${ }^{*} P<.05$.

\subsection{Data analysis}

All comparisons were calculated using paired, 2-tailed Student $t$ test. $P$ values less than .05 were considered significant. Tests for correlations were calculated using

Table 1

Metabolic characteristics and changes after intervention

\begin{tabular}{|c|c|c|c|c|}
\hline & Before VLCD & After VLCD & $\%$ Change & $P$ value \\
\hline Duration of VLCD, $\mathrm{d}$ & $53(3.8)$ & & & \\
\hline Age at baseline, $\mathrm{y}$ & $32.3(1.0)$ & & & \\
\hline Weight, $\mathrm{kg}$ & $93.1(3.0)$ & $82.4(3.1)$ & $-11.5 \%$ & $<.01$ \\
\hline FFM, kg & $51.4(1.4)$ & $49.3(1.5)$ & $-4.1 \%$ & $<.05$ \\
\hline BMI, $\mathrm{kg} / \mathrm{m}^{2}$ & $33.4(0.9)$ & $29.3(1.1)$ & $-12.3 \%$ & $<.01$ \\
\hline Fasting plasma glucose, $\mathrm{mmol} / \mathrm{L}$ & $5.72(0.14)$ & $5.38(0.11)$ & $-5.9 \%$ & $<.01$ \\
\hline Fasting plasma insulin, $\mathrm{pmol} / \mathrm{L}$ & $59(11)$ & $26(5)$ & $-56.0 \%$ & $<.05$ \\
\hline HOMA IR & $1.14(0.22)$ & $0.63(0.10)$ & $-44.7 \%$ & $<.05$ \\
\hline $\mathrm{AUC}_{\text {glucose }}, \mathrm{mmol} /(\mathrm{L} 120 \mathrm{~min})$ & $829(45)$ & $773(41)$ & $-6.8 \%$ & NS \\
\hline $\mathrm{AUC}_{\text {insulin }}, \mathrm{nmol} /(\mathrm{L} 120 \mathrm{~min})$ & $37.9(5.1)$ & $25.9(4.1)$ & $-31.5 \%$ & $<.05$ \\
\hline ISIcomposite & $4.3(0.6)$ & $6.0(0.8)$ & $+39.5 \%$ & $<.05^{*}$ \\
\hline $\mathrm{T} 3, \mathrm{pmol} / \mathrm{L}(\mathrm{n}=8)$ & $4.90(0.15)$ & $4.41(0.15)$ & $-10.0 \%$ & $<.05$ \\
\hline Plasma FFA, mmol/L $(\mathrm{n}=8)$ & $0.48(0.04)$ & $0.78(0.14)$ & $+62.5 \%$ & NS (.1) \\
\hline RER & $0.87(0.01)$ & $0.79(0.02)$ & $-9.2 \%$ & $<.05$ \\
\hline
\end{tabular}

Data are given as means (SE) unless otherwise stated. ISIcomposite (Matsuda index) was calculated from the 2-hour OGTT according to Matsuda and Defronzo [19]. $\mathrm{RER}=\mathrm{VCO}_{2} / \mathrm{VO}_{2}$. RCR indicates respiratory control ratio; NS, not significant.

* $P$ value calculated after $\log$ transformation of ISI values to achieve a normal distribution of values. 


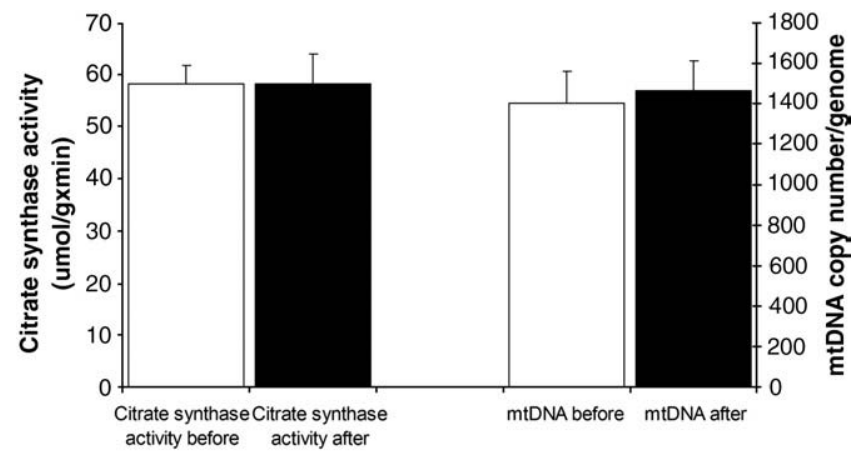

Fig. 3. Change in skeletal muscle citrate synthase activity and muscle mtDNA content (mtDNA per genome) as a result of more than $10 \%$ weight loss.

Pearson correlation coefficient $(r)$. If the criterion of normal distribution of values was not met, values were $\log$ transformed to obtain normalization of distribution. All data on subject characteristics are given as mean (SD). All other data are expressed as means (SE).

\section{Results}

Nine subjects completed the VLCD and were available for follow-up. Two subjects became pregnant during the intervention period, 5 dropped out because of lack of compliance, and 1 study subject completed the intervention period but did not accept the second muscle biopsy. Baseline characteristics did not differ between completers and noncompleters (data not shown).

The subjects lost on average $11.5 \%$ of their baseline weight during VLCD, with a mean length of VLCD treatment of 53 days (SE, 3.8) (Fig. 1). The weight loss
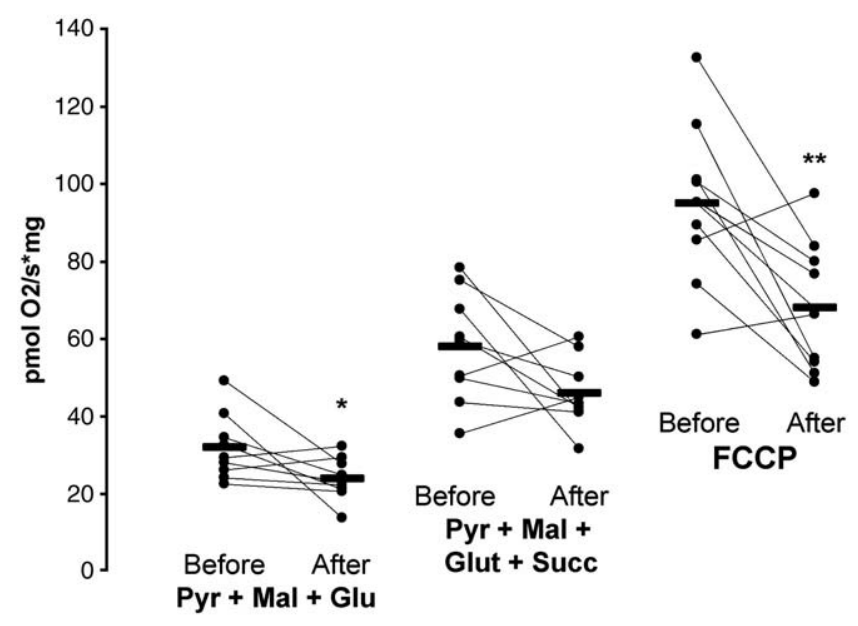

Fig. 4. Individual changes in mitochondrial respiration in response to weight loss. Oxygen consumption measured per milligram muscle. ${ }^{*} P$ equal to $.05 . * * P .05$. Mal + Glut: malate and glutamate, substrates for complex I. $\mathrm{Mal}+\mathrm{Glut}+$ Succ: malate, glutamate, and succinate, substrates for complex I and II. FCCP: uncoupler, total electron transport capacity.
Table 2

Effect of intervention; muscle biopsy analysis

\begin{tabular}{lccll}
\hline & $\begin{array}{l}\text { Before } \\
\text { VLCD }\end{array}$ & $\begin{array}{l}\text { After } \\
\text { VLCD }\end{array}$ & \% change & $P$ value \\
& $194(57)$ & $149(40)$ & $-23 \%$ & NS \\
IMTG $(\mathrm{n}=8)(\mathrm{nmol} / \mathrm{mg})$ & $19.6(5.76)$ & $92.2(8.0)$ & $+2.9 \%$ & NS \\
Glycogen $(\mathrm{nmol} / \mathrm{mg})$ & 89.6 & $2.8(0.3)$ & $+3.7 \%$ & NS \\
RCR & $2.7(0.6)$ & $2.06)$ & NS $(.06)$ \\
\hline
\end{tabular}

Data are given as means (SE). RCR was measured using respirometry as state 3/state 2. Average baseline UCP3 was set at $100 \%$.

resulted in significant decreases in fasting plasma glucose and fasting plasma insulin, thus improving insulin sensitivity estimated with the HOMA-IR index (Table 1). Furthermore, the ISIcomposite (Matsuda index) calculated from the 2-hour OGTT improved significantly (Table 1). Glucose area under the curve (AUC) did not change as a result of weight loss, but insulin AUC decreased significantly (Table 1). Time courses of glucose and insulin concentrations during OGTT are shown in Fig. 2.

Caloric restriction did not affect citrate synthase activity or mtDNA copy number per genome (Fig. 3). Mitochondrial respiration per milligram of tissue decreased by $21 \%$ to $28 \%$ depending on the substrates used. State 3 respiration with malate $(2 \mathrm{mmol} / \mathrm{L})$, glutamate $(10 \mathrm{mmol} / \mathrm{L})$, and ADP $(5 \mathrm{mmol} / \mathrm{L}$ ) was reduced from 31.8 (SE, 2.9) to 23.8 (SE, 1.8) $\mathrm{pmol}_{2}$ per second per milligram $(P=.05)$; and uncoupled respiration after titration with FCCP $(0.5-$ $2 \mu \mathrm{mol} / \mathrm{L}$ ) fell from 94.9 (SE, 7.1) to 68.0 (SE, 5.7) pmol $\mathrm{O}_{2}$ per second per milligram $(P<.05)$. State 3 respiration with malate, glutamate, succinate $(10 \mathrm{mmol} / \mathrm{L})$, and ADP decreased, approaching statistical significance $(P=.07)$ (Fig. 4). When mitochondrial respiration was corrected for citrate synthase activity (as a marker for mitochondrial content), we found similar differences (data not shown). We were not able to detect any correlation between mitochondrial respiration and insulin resistance.
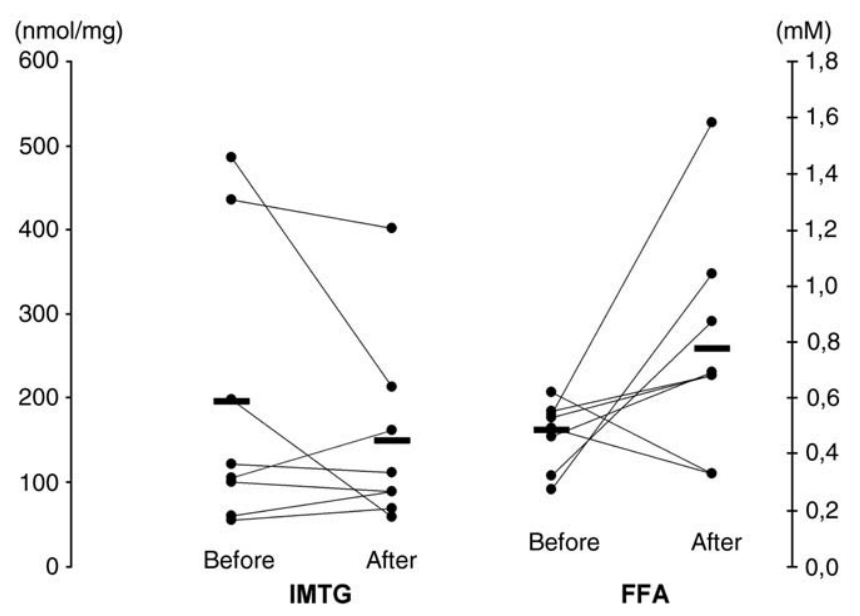

Fig. 5. Individual changes in IMTG $(n=8)$ and FFA $(n=8)$ in response to more than $10 \%$ weight loss. The changes in average IMTG and FFA are not significant. 
Plasma levels of FFA increased in 6 of 8 subjects. Average values increased from 0.48 (SE, 0.04) to 0.78 (SE, $0.14) \mathrm{mmol} / \mathrm{L}$ after treatment $(P=.1)$, indicating that subjects were still in a catabolic state. The change in FFA concentration did not correlate with the change in mitochondrial respiration. Intramyocellular triglyceride, however, did not change significantly (Table 2). Three subjects had increased and 5 subjects lost IMTG during the VLCD. Individual changes in IMTG and FFA are shown in Fig. 5.

Respiratory exchange ratio (RER) decreased significantly from 0.87 (SE, 0.01) before weight loss to 0.79 (SE, 0.02) after weight loss $(P<.05)$. Serum concentrations of T3 decreased significantly (Table 1), but the changes in concentrations of $\mathrm{T} 3$ did not correlate with changes in maximal coupled mitochondrial respiration (substrates: malate, glutamate, succinate, and ADP) $\left(r^{2}=0.44, P<.1\right)$ but correlated with changes in basal metabolic rate measured with indirect calorimetry $\left(r^{2}=0.53, P<.05\right.$, data not shown $)$. It was not possible to detect a correlation between mitochondrial oxygen consumption and whole-body oxygen consumption in the resting state.

\section{Discussion}

This study provides evidence of increased whole-body fat oxidation in the postprandial overnight-fasted state but a paradoxical reduction in mitochondrial respiration after weight loss and improvements in glucose metabolism. These results do not support a direct positive relationship between mitochondrial function and insulin sensitivity in young obese women.

This study is the first to demonstrate a reduction in mitochondrial respiration with a concomitant improvement in insulin sensitivity. This pattern is in contrast to reports of a strong positive relationship between insulin sensitivity and indices of mitochondrial respiratory capacity $[22,23]$. The method of permeabilized muscle fibers allows us to directly measure mitochondrial function in a tissue sample ex vivo; and the data we obtain reflect the activity of the citric acid cycle, the electron transport system, and all the oxidative enzymes combined. The data indicate that intrinsic downregulation of mitochondrial activity takes place during a period of caloric restriction because we find no evidence of a reduction in mitochondrial number (as demonstrated by an unchanged number of mtDNA).

Our subjects were studied while they were still on a VLCD and hence before weight stabilization, and the catabolic state has been shown to decrease metabolic activity [24]. However, our aim was to study the effects of weight loss on mitochondrial respiration and markers of insulin sensitivity, regardless of phase of weight regulation. Furthermore, only women were studied, limiting the generalizability of our results to this sex. We measured fasting plasma glucose and insulin and calculated HOMA-IR as a marker of insulin sensitivity, and performed 2-hour
OGTTs to calculate the ISIcomposite [19]. The HOMA-IR method provides more information on the hepatic insulin sensitivity in the fasting state, and glucose clamp studies would have given more information on the peripheral insulin sensitivity at high insulin concentrations. Nevertheless, HOMA-IR and ISIcomposite correlate reasonably with clamp data for insulin sensitivity [19,25], especially in nondiabetic subjects.

Only a few studies have been conducted on the effect of weight loss on oxidative capacity in human skeletal muscle [26-28]. Toledo et al [28] recently described how weight loss without exercise decreased IMTG, improved insulin action, but did not change mitochondrial capacity in obese individuals. Mitochondrial capacity was measured as nicotinamide adenine dinucleotide (NADH) oxidase activity, cardiolipin content, and mtDNA copy number per nuclear DNA. Mitochondrial density did not change, but mitochondrial size decreased as a response to weight loss. The present study partly confirms the findings of Toledo et al that improvements in insulin sensitivity can occur independently of changes in mitochondrial capacity. In contrast to Toledo et al, we find a reduction in mitochondrial respiration after weight loss; but this could be due to the fact that the subjects in our study experienced a larger and more rapid weight loss ( $>10 \%$ in 8 weeks compared with $>7 \%$ in 20 weeks). An important distinction between the studies is that our mitochondrial respirometry data represent the integrated function of the entire electron system and adenylatecontrolled phosphorylation capacity in which multiple levels of intrinsic regulatory control are exerted, for example, allosteric control of cytochrome $c$, sensitivity to ADP, mitochondrial creatine kinase, and activity of the mitochondrial adenylate transporter ANT.

Caloric restriction is reported to stimulate mitochondrial biogenesis in both rodents [29] and humans [30]. The increase in mitochondrial content is thought to lead to less reactive oxygen species production due to less electron transport chain activity in each mitochondrion. The decrease in reactive oxygen species production is beneficial for the longevity of the cell. Civitarese et al [30] reported an increase in mtDNA copy number after 6 months of caloric restriction, but an unchanged citrate synthase activity. We were unable to find differences in mtDNA copy number or citrate synthase activity. The difference between the study of Civitarese et al and our study could be explained by differences in weight and rate of weight loss. Nevertheless, our observation of an intrinsic down-regulation of electron transport and less electron transport chain activity could be the mechanism behind the positive effect of caloric restriction on cell longevity.

The regulation of mitochondrial activity is still unclear. Thyroid hormone has been known for many years to have an effect on energy homeostasis and mitochondrial function [31-33], and it has been suggested that T3 exerts its effects on the mitochondrion on different levels: either (1) by indirect mechanisms (changing expression of nuclear 
encoded respiratory genes) or (2) directly by changing levels of coupling between respiration and ATP production [34]. We can confirm that levels of thyroid hormone and mitochondrial activity are correlated, but we are not able to confirm that thyroid hormone has direct effects on mitochondrial efficiency in human skeletal muscle because we find no change in the level of respiratory control ratios after a weight loss-induced decrease in T3 levels. Future research is clearly needed on the intrinsic regulation of mitochondrial activity.

The total body fat oxidation increased during the VLCD This was evidenced by a decrease in RER and a trend toward increases in FFA and UCP3. Elevation of FFA by lipid infusion has been shown to limit mitochondrial ATP synthesis rate and induce insulin resistance [11]. However, the induction of insulin resistance occurs at a 3- to 4-hour delay after the rise in FFA, suggesting that FFA has to be reesterified to cause insulin resistance [35]. Caloric restriction leads to increased lipolysis; and we find a trend for increased levels of FFA but unchanged levels of IMTG, whereas indices of insulin sensitivity improved. This does not support the notion that IMTG and insulin resistance are closely related or that FFA per se causes insulin resistance.

Weight loss remains the cornerstone for improving insulin sensitivity. The breakdown of intrahepatic and intramyocellular lipid has beneficial effects on whole-body glucose metabolism. The oxidative capacity of skeletal muscle seems sufficient for the mobilization of intramuscular lipid [28]. It is only when weight loss is combined with physical training that oxidative capacity increases [28]. Yet, it has recently been reported that 5 weeks of high-fat diet in mice, without altering exercise level, leads to increased IMTG and insulin resistance but also increased mitochondrial biogenesis [36]. It has been speculated that the decrease in oxidative capacity found in type 2 diabetes mellitus causes accumulation of IMTG and insulin resistance $[37,38]$. From this and other studies $[27,28,36,39]$, it does not seem that oxidative capacity limits the mobilization of IMTG or is causally involved in the development of insulin resistance; but a slight decrease in oxidative capacity could over a long period, in theory, lead to accumulation of IMTG. From this perspective, physical activity remains the best way of preventing insulin resistance and type 2 diabetes mellitus.

In conclusion, we have shown that VLCD-induced weight loss improves glucose homeostasis and reduces mitochondrial respiration. Our results do not support a direct relationship between mitochondrial function and insulin resistance in young obese women and do not support a direct relationship between IMTG and insulin sensitivity in young obese women during weight loss.

\section{References}

[1] Lillioja S, Mott DM, Howard BV, et al. Impaired glucose tolerance as a disorder of insulin action. Longitudinal and cross-sectional studies in Pima Indians. N Engl J Med 1988;318:1217-25.
[2] Krssak M, Falk PK, Dresner A, et al. Intramyocellular lipid concentrations are correlated with insulin sensitivity in humans: a 1H NMR spectroscopy study. Diabetologia 1999;42:113-6.

[3] Perseghin G, Scifo P, De CF, et al. Intramyocellular triglyceride content is a determinant of in vivo insulin resistance in humans: a $1 \mathrm{H}-13 \mathrm{C}$ nuclear magnetic resonance spectroscopy assessment in offspring of type 2 diabetic parents. Diabetes 1999;48:1600-6.

[4] Petersen KF, Dufour S, Befroy D, et al. Impaired mitochondrial activity in the insulin-resistant offspring of patients with type 2 diabetes. N Engl J Med 2004;350:664-71.

[5] Petersen KF, Dufour S, Shulman GI. Decreased insulin-stimulated ATP synthesis and phosphate transport in muscle of insulin-resistant offspring of type 2 diabetic parents. PLoS Med 2005;2:e233.

[6] Shulman GI. Cellular mechanisms of insulin resistance. J Clin Invest 2000;106:171-6.

[7] Mogensen M, Sahlin K, Fernstrom M, et al. Mitochondrial respiration is decreased in skeletal muscle of patients with type 2 diabetes. Diabetes 2007;56:1592-9.

[8] Boushel R, Gnaiger E, Schjerling P, et al. Patients with type 2 diabetes have normal mitochondrial function in skeletal muscle. Diabetologia 2007;50:790-6.

[9] Morino K, Petersen KF, Dufour S, et al. Reduced mitochondrial density and increased IRS-1 serine phosphorylation in muscle of insulin-resistant offspring of type 2 diabetic parents. J Clin Invest 2005;115:3587-93.

[10] Rabol R, Boushel R, Dela F. Mitochondrial oxidative function and type 2 diabetes. Appl Physiol Nutr Metab 2006;31:675-83.

[11] Brehm A, Krssak M, Schmid AI, et al. Increased lipid availability impairs insulin-stimulated ATP synthesis in human skeletal muscle. Diabetes 2006;55:136-40

[12] Schrauwen P, Hesselink MK. Oxidative capacity, lipotoxicity, and mitochondrial damage in type 2 diabetes. Diabetes 2004;53:1412-7.

[13] Kunz WS, Kuznetsov AV, Schulze W, et al. Functional characterization of mitochondrial oxidative phosphorylation in saponin-skinned human muscle fibers. Biochim Biophys Acta 1993;1144:46-53.

[14] Kuznetsov AV, Wiedemann FR, Winkler K, et al. Use of saponinpermeabilized muscle fibers for the diagnosis of mitochondrial diseases. Biofactors 1998;7:221-3.

[15] Saks VA, Veksler VI, Kuznetsov AV, et al. Permeabilized cell and skinned fiber techniques in studies of mitochondrial function in vivo. Mol Cell Biochem 1998;184:81-100.

[16] Bergstrom J. Percutaneous needle biopsy of skeletal muscle in physiological and clinical research. Scand J Clin Lab Invest 1975; 35:609-16.

[17] Lowry OH, Passonneau JV. Some recent refinements of quantitative histochemical analysis. Curr Probl Clin Biochem 1971;3:63-84.

[18] Kiens B, Richter EA. Types of carbohydrate in an ordinary diet affect insulin action and muscle substrates in humans. Am J Clin Nutr 1996; 63:47-53.

[19] Matsuda M, Defronzo RA. Insulin sensitivity indices obtained from oral glucose tolerance testing: comparison with the euglycemic insulin clamp. Diabetes Care 1999;22:1462-70.

[20] Hesselink MK, Greenhaff PL, Constantin-Teodosiu D, et al. Increased uncoupling protein 3 content does not affect mitochondrial function in human skeletal muscle in vivo. J Clin Invest 2003;111:479-86.

[21] Schrauwen P, Schaart G, Saris WH, et al. The effect of weight reduction on skeletal muscle UCP2 and UCP3 mRNA expression and UCP3 protein content in type II diabetic subjects. Diabetologia 2000; 43:1408-16.

[22] Kelley DE, He J, Menshikova EV, et al. Dysfunction of mitochondria in human skeletal muscle in type 2 diabetes. Diabetes 2002;51:2944-50.

[23] Ritov VB, Menshikova EV, He J, et al. Deficiency of subsarcolemmal mitochondria in obesity and type 2 diabetes. Diabetes 2005;54:8-14.

[24] Weinsier RL, Nagy TR, Hunter GR, et al. Do adaptive changes in metabolic rate favor weight regain in weight-reduced individuals? An examination of the set-point theory. Am J Clin Nutr 2000;72:1088-94.

[25] Wallace TM, Levy JC, Matthews DR. Use and abuse of HOMA modeling. Diabetes Care 2004;27:1487-95. 
[26] Kern PA, Simsolo RB, Fournier M. Effect of weight loss on muscle fiber type, fiber size, capillarity, and succinate dehydrogenase activity in humans. J Clin Endocrinol Metab 1999;84:4185-90.

[27] Simoneau JA, Veerkamp JH, Turcotte LP, et al. Markers of capacity to utilize fatty acids in human skeletal muscle: relation to insulin resistance and obesity and effects of weight loss. FASEB J 1999;13: 2051-60.

[28] Toledo FG, Menshikova EV, Azuma K, et al. Mitochondrial capacity in skeletal muscle is not stimulated by weight loss despite increases in insulin action and decreases in intramyocellular lipid content. Diabetes 2008;57:987-94

[29] Nisoli E, Tonello C, Cardile A, et al. Calorie restriction promotes mitochondrial biogenesis by inducing the expression of eNOS. Science 2005;310:314-7.

[30] Civitarese AE, Carling S, Heilbronn LK, et al. Calorie restriction increases muscle mitochondrial biogenesis in healthy humans. PLoS Med 2007;4:e76.

[31] Goglia F, Silvestri E, Lanni A. Thyroid hormones and mitochondria. Biosci Rep 2002;22:17-32.
[32] Silva JE. Thermogenic mechanisms and their hormonal regulation. Physiol Rev 2006;86:435-64.

[33] Soboll S. Thyroid hormone action on mitochondrial energy transfer. Biochim Biophys Acta 1993;1144:1-16.

[34] Goglia F, Moreno M, Lanni A. Action of thyroid hormones at the cellular level: the mitochondrial target. FEBS Lett 1999;452:115-20.

[35] Boden G, Lebed B, Schatz M, et al. Effects of acute changes of plasma free fatty acids on intramyocellular fat content and insulin resistance in healthy subjects. Diabetes 2001;50:1612-7.

[36] Hancock CR, Han DH, Chen M, et al. High-fat diets cause insulin resistance despite an increase in muscle mitochondria. Proc Natl Acad Sci U S A 2008;105:7815-20.

[37] Lowell BB, Shulman GI. Mitochondrial dysfunction and type 2 diabetes. Science 2005;307:384-7.

[38] Petersen KF, Shulman GI. Etiology of insulin resistance. Am J Med 2006;119:S10-6.

[39] Nair KS, Bigelow ML, Asmann YW, et al. Asian Indians have enhanced skeletal muscle mitochondrial capacity to produce ATP in association with severe insulin resistance. Diabetes 2008;57:1166-75. 